\title{
Effects of exogenous ketone supplementation on blood ketone, glucose, triglyceride, and lipoprotein levels in Sprague-Dawley rats
}

Shannon L. Kesl ${ }^{1 *}$, Angela M. Poff ${ }^{1}$, Nathan P. Ward ${ }^{1}$, Tina N. Fiorelli ${ }^{1}$, Csilla Ari ${ }^{1}$, Ashley J. Van Putten ${ }^{1}$, Jacob W. Sherwood ${ }^{1}$, Patrick Arnold ${ }^{2}$ and Dominic P. D'Agostino ${ }^{1}$

\begin{abstract}
Background: Nutritional ketosis induced by the ketogenic diet (KD) has therapeutic applications for many disease states. We hypothesized that oral administration of exogenous ketone supplements could produce sustained nutritional ketosis $(>0.5 \mathrm{mM})$ without carbohydrate restriction.

Methods: We tested the effects of 28-day administration of five ketone supplements on blood glucose, ketones, and lipids in male Sprague-Dawley rats. The supplements included: 1,3-butanediol (BD), a sodium/potassium $\beta$ hydroxybutyrate (BHB) mineral salt (BMS), medium chain triglyceride oil (MCT), BMS + MCT 1:1 mixture, and 1,3 butanediol acetoacetate diester (KE). Rats received a daily 5-10 g/kg dose of their respective ketone supplement via intragastric gavage during treatment. Weekly whole blood samples were taken for analysis of glucose and $\beta \mathrm{HB}$ at baseline and, $0.5,1,4,8$, and $12 \mathrm{~h}$ post-gavage, or until $\beta \mathrm{HB}$ returned to baseline. At 28 days, triglycerides, total cholesterol and high-density lipoprotein (HDL) were measured.
\end{abstract}

Results: Exogenous ketone supplementation caused a rapid and sustained elevation of $\beta H B$, reduction of glucose, and little change to lipid biomarkers compared to control animals.

Conclusions: This study demonstrates the efficacy and tolerability of oral exogenous ketone supplementation in inducing nutritional ketosis independent of dietary restriction.

Keywords: Ketogenic diet, Ketone ester, Ketone supplement, Appetite, $\beta$-hydroxybutyrate, Hyperketonemia, Triglycerides

\section{Background}

Emerging evidence supports the therapeutic potential of the ketogenic diet (KD) for a variety of disease states, leading investigators to research methods of harnessing the benefits of nutritional ketosis without the dietary restrictions. The KD has been used as an effective nonpharmacological therapy for pediatric intractable seizures since the 1920s [1-3]. In addition to epilepsy, the ketogenic diet has elicited significant therapeutic effects

\footnotetext{
* Correspondence: skes|@health.usf.edu

'Department of Molecular Pharmacology and Physiology, Morsani College of Medicine, University of South Florida, 12901 Bruce B. Downs Blvd. MDC8,

Tampa, FL 33612, USA

Full list of author information is available at the end of the article
}

for weight loss and type-2 diabetes (T2D) [4]. Several studies have shown significant weight loss on a high fat, low carbohydrate diet without significant elevations of serum cholesterol [5-12]. Another study demonstrated the safety and benefits of long-term application of the KD in T2D patients. Patients exhibited significant weight loss, reduction of blood glucose, and improvement of lipid markers after eating a well-formulated $\mathrm{KD}$ for 56 weeks [13]. Recently, researchers have begun to investigate the use of the KD as a treatment for acne, polycystic ovary syndrome (PCOS), cancer, amyotrophic lateral sclerosis (ALS), traumatic brain injury (TBI) and Alzheimer's disease (AD) with promising preliminary results [14-26]. 
The classical KD consists of a 4:1 ratio of fat to protein and carbohydrate, with $80-90 \%$ of total calories derived from fat [27]. The macronutrient ratio of the KD induces a metabolic shift towards fatty acid oxidation and hepatic ketogenesis, elevating the ketone bodies acetoacetate $(\mathrm{AcAc})$ and $\beta$-hydroxybutyrate $(\beta \mathrm{HB})$ in the blood. Acetone, generated by decarboxylation of AcAc, has been shown to have anticonvulsant properties [28-32]. Ketone bodies are naturally elevated to serve as alternative metabolic substrates for extra-hepatic tissues during the prolonged reduction of glucose availability, suppression of insulin, and depletion of liver glycogen, such as occurs during starvation, fasting, vigorous exercise, calorie restriction, or the $\mathrm{KD}$. Although the $\mathrm{KD}$ has clear therapeutic potential, several factors limit the efficacy and utility of this metabolic therapy for widespread clinical use. Patient compliance to the KD can be low due to the severe dietary restriction - the diet being generally perceived as unpalatable - and intolerance to high-fat ingestion. Maintaining ketosis can be difficult as consumption of even a small quantity of carbohydrates or excess protein can rapidly inhibit ketogenesis [33, 34]. Furthermore, enhanced ketone body production and tissue utilization by the tissues can take several weeks (keto-adaptation), and patients may experience mild hypoglycemic symptoms during this transitional period [35].

Recent studies suggest that many of the benefits of the $\mathrm{KD}$ are due to the effects of ketone body metabolism. Interestingly, in studies on T2D patients, improved glycemic control, improved lipid markers, and retraction of insulin and other medications occurred before weight loss became significant. Both $\beta \mathrm{HB}$ and AcAc have been shown to decrease mitochondrial reactive oxygen species (ROS) production [36-39]. Veech et al. have summarized the potential therapeutic uses for ketone bodies [28, 40]. They have demonstrated that exogenous ketones favorably alter mitochondrial bioenergetics to reduce the mitochondrial NAD couple, oxidize the co-enzyme Q, and increase the $\Delta G^{\prime}$ (free enthalpy) of ATP hydrolysis [41]. Ketone bodies have been shown to increase the hydraulic efficiency of the heart by $28 \%$, simultaneously decreasing oxygen consumption while increasing ATP production [42]. Thus, elevated ketone bodies increase metabolic efficiency and as a consequence, reduce superoxide production and increase reduced glutathione [28]. Sullivan et al. demonstrated that mice fed a KD for 10-12 days showed increased hippocampal uncoupling proteins, indicative of decreased mitochondrial-produced ROS [43]. Bough et al. showed an increase of mitochondrial biogenesis in rats maintained on a KD for 4-6 weeks $[44,45]$. Recently, Shimazu et al. reported that $\beta \mathrm{HB}$ is an exogenous and specific inhibitor of class I histone deacetylases (HDACs), which confers protection against oxidative stress [38]. Ketone bodies have also been shown to suppress inflammation by decreasing the inflammatory markers TNF-a, IL-6, IL-8, MCP-1, E-selectin, I-CAM, and PAI- $18,46,47]$. Therefore, it is thought that ketone bodies themselves confer many of the benefits associated with the KD.

Considering both the broad therapeutic potential and limitations of the $\mathrm{KD}$, an oral exogenous ketone supplement capable of inducing sustained therapeutic ketosis without the need for dietary restriction would serve as a practical alternative. Several natural and synthetic ketone supplements capable of inducing nutritional ketosis have been identified. Desrochers et al. elevated ketone bodies in the blood of pigs $(>0.5 \mathrm{mM})$ using exogenous ketone supplements: ( $R, S)-1,3$ butanediol and (,$S)-1,3$ butanediol-acetoacetate monoesters and diester [48]. In 2012, Clarke et al. demonstrated the safety and efficacy of chronic oral administration of a ketone monoester of $\mathrm{R}-\beta \mathrm{HB}$ in rats and humans $[49,50]$. Subjects maintained elevated blood ketones without dietary restriction and experienced little to no adverse side effects, demonstrating the potential to circumvent the restrictive diet typically needed to achieve therapeutic ketosis. We hypothesized that exogenous ketone supplements could produce sustained hyperketonemia $(>0.5 \mathrm{mM})$ without dietary restriction and without negatively influencing metabolic biomarkers, such as blood glucose, total cholesterol, HDL, LDL, and triglycerides. Thus, we measured these biomarkers during a 28-day administration of the following ketone supplements in rats: naturally-derived ketogenic supplements included medium chain triglyceride oil (MCT), sodium/potassium - $\beta \mathrm{HB}$ mineral salt (BMS), and sodium/potassium $-\beta \mathrm{HB}$ mineral salt + medium chain triglyceride oil 1:1 mixture (BMS + $\mathrm{MCT}$ ) and synthetically produced ketogenic supplements included 1, 3-butanediol (BD), 1, 3-butanediol acetoacetate diester/ ketone ester (KE).

\section{Methods}

\section{Synthesis and formulation of ketone supplements}

KE was synthesized as previously described [29]. BMS is a novel agent (sodium/potassium- $\beta \mathrm{HB}$ mineral salt) supplied as a $50 \%$ solution containing approximately $375 \mathrm{mg} / \mathrm{g}$ of pure $\beta \mathrm{HB}$ and $125 \mathrm{mg} / \mathrm{g}$ of sodium/potassium. Both KE and BMS were developed and synthesized in collaboration with Savind Inc. Pharmaceutical grade MCT oil ( $65 \%$ caprylic triglyceride; $45 \%$ capric triglyceride) was purchased from Now Foods (Bloomingdale, IL). BMS was formulated in a 1:1 ratio with MCT at the University of South Florida (USF), yielding a final mixture of $25 \%$ water, $25 \%$ pure $\beta \mathrm{HB}$ mineral salt and $50 \%$ MCT. BD was purchased from Sigma-Aldrich (Prod \# B84785, Milwaukee, WI).

\section{Daily gavage to induce dietary ketosis}

Animal procedures were performed in accordance with the University of South Florida Institutional Animal 
Care and Use Committee (IACUC) guidelines (Protocol \#0006R). Juvenile male Sprague-Dawley rats (275-325 g, Harlan Laboratories) were randomly assigned to one of six study groups: control (water, $n=11), \mathrm{BD}(n=11), \mathrm{KE}$ $(n=11)$, MCT $(n=10)$, BMS $(n=11)$, or BMS + MCT $(n=12)$. Caloric density of standard rodent chow and dose of ketone supplements are listed in Table 1. On days $1-14$, rats received a $5 \mathrm{~g} / \mathrm{kg}$ body weight dose of their respective treatments via intragastric gavage. Dosage was increased to $10 \mathrm{~g} / \mathrm{kg}$ body weight for the second half of the study (days 15-28) for all groups except BD and KE to prevent excessive hyperketonemia (ketoacidosis). Each daily dose of BMS would equal $\sim 1000-1500 \mathrm{mg}$ of $\beta \mathrm{HB}$, depending on the weight of the animal. Intragastric gavage was performed at the same time daily, and animals had ad libitum access to standard rodent chow 2018 (Harlan Teklad) for the duration of the study. The macronutrient ratio the standard rodent chow was $62.2,23.8$ and $14 \%$ of carbohydrates, protein and fat respectively.

\section{Measurement and analysis of blood glucose, ketones, and lipids}

Every 7 days, animals were briefly fasted $(4 \mathrm{~h}$, water available) prior to intragastric gavage to standardize levels of blood metabolites prior to glucose and $\beta \mathrm{HB}$ measurements at baseline. Baseline (time 0) was immediately prior to gavage. Whole blood samples $(10 \mu \mathrm{L})$ were taken from the saphenous vein for analysis of glucose and $\beta H B$ levels with the commercially available glucose and ketone monitoring system Precision Xtra $^{\text {Th }}$ (Abbott Laboratories, Abbott Park, IL). Blood glucose and $\beta \mathrm{HB}$ were measured at $0,0.5,1,4,8$, and $12 \mathrm{~h}$ after test substance administration, or until $\beta \mathrm{HB}$ returned to baseline levels. Food was returned to animals after blood analysis at time 0 and gavage. At baseline and week 4 , whole blood samples $(10 \mu \mathrm{L})$ were taken from the saphenous vein immediately prior to gavage (time 0) for analysis of total cholesterol, high-density lipoprotein (HDL), and triglycerides with the commercially available CardioChek ${ }^{\mathrm{m}}$ blood lipid analyzer (Polymer Technology Systems, Inc., Indianapolis, IN). Low-density lipoprotein (LDL) cholesterol was calculated from the three measured lipid levels using the Friedewald equation: (LDL Cholesterol $=$ Total Cholesterol - HDL $-($ Triglycerides/5) $)[51$, 52]. Animals were weighed once per week to track changes in body weight associated with hyperketonemia.

\section{Organ weight and collection}

On day 29, rats were sacrificed via deep isoflurane anesthesia, exsanguination by cardiac puncture, and decapitation 4-8 h after intragastric gavage, which correlated to the time range where the most significantly elevated blood $\beta \mathrm{HB}$ levels were observed. Brain, lungs, liver, kidneys, spleen and heart were harvested, weighed (AWS$10001 \mathrm{~kg}$ portable digital scale (AWS, Charleston, SC)), and flash-frozen in liquid nitrogen or preserved in $4 \%$ paraformaldehyde for future analysis.

\section{Statistics}

All data are presented as the mean \pm standard deviation (SD). Data analysis was performed using GraphPad PRISM $^{\mathrm{mm}}$ version 6.0a and IBM SPSS Statistics 22.0. Results were considered significant when $\mathrm{p}<0.05$. Triglyceride and lipoprotein profile data were analyzed using One-Way ANOVA. Blood ketone and blood glucose were compared to control at the applicable time points using a Two-Way ANOVA. Correlation between blood $\beta \mathrm{HB}$ and glucose levels in ketone supplemented rats was compared to controls using ANCOVA analysis. Organ and body weights were analyzed using One-Way ANOVA. Basal blood ketone and blood glucose levels were analyzed using Two-Way ANOVA. All mean comparisons were carried out using Tukey's multiple comparisons post-hoc test.

\section{Results}

Effect of ketone supplementation on triglycerides and lipoproteins

Baseline measurements showed no significant changes in triglycerides or the lipoproteins (data not shown). Data represent triglyceride and lipoprotein concentrations measured after 4 weeks of daily exogenous ketone supplementation. No significant change in total cholesterol was observed at 4 weeks for any of the ketone treatment groups compared to control. (Fig. 1a). No

Table 1 Caloric density and dose of ketone supplements

\begin{tabular}{|c|c|c|c|c|c|c|c|}
\hline Macronutrient Information & Standard Diet & Water & $\mathrm{BMS}+\mathrm{MCT}$ & BMS & MCT & KE & $\mathrm{BD}$ \\
\hline$\%$ Cal from Fat & 18.0 & 0.0 & 50.0 & N/A & 100.0 & N/A & N/A \\
\hline$\%$ Cal from Protein & 24.0 & 0.0 & N/A & N/A & 0.0 & N/A & N/A \\
\hline \% Cal from Carbohydrates & 58.0 & 0.0 & N/A & N/A & 0.0 & N/A & N/A \\
\hline Total Caloric Density (Kcal/g) & 3.1 & 0.0 & 5.1 & 1.9 & 8.3 & 5.6 & 6.0 \\
\hline Dose 0-14 Days (g/kg) & ad libitum & $\mathrm{N} / \mathrm{A}$ & 5.0 & 5.0 & 5.0 & 5.0 & 5.0 \\
\hline Dose 15-28 Days (g/kg) & ad libitum & N/A & 10.0 & 10.0 & 10.0 & 5.0 & 5.0 \\
\hline
\end{tabular}



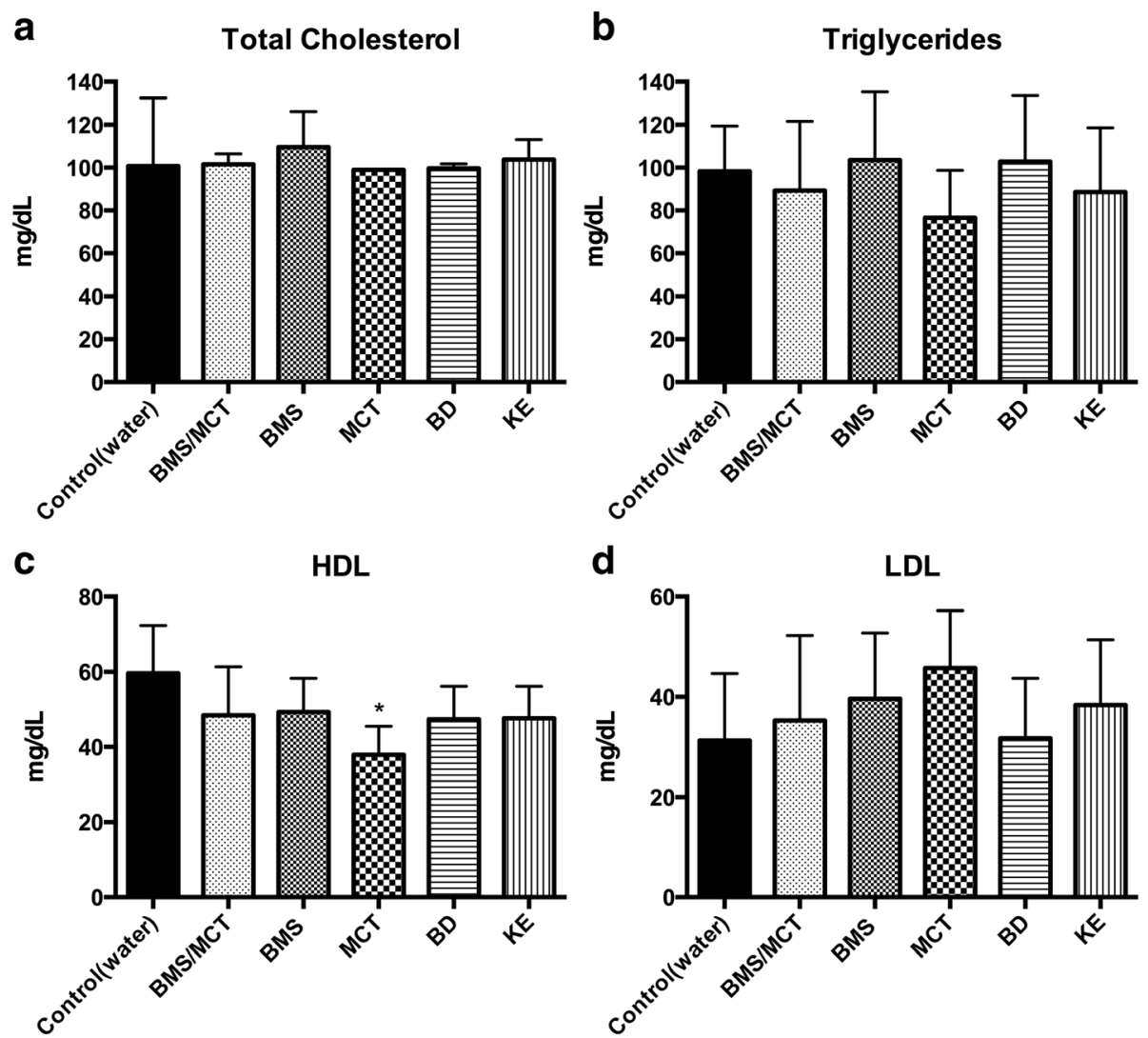

Fig. 1 Effects of ketone supplementation on triglycerides and lipoproteins: Ketone supplementation causes little change in triglycerides and lipoproteins over a 4-week study. Graphs show concentrations at 4-weeks of total cholesterol (a), Triglycerides (b), LDL (c), and HDL (d), MCT supplemented rats had signfiicantly reduced concentration of HDL blood levels compared to control $(p<0.001)(\mathbf{b})$. One-Way ANOVA with Tukey's post hoc test, results considered significant if $p<0.05$. Error bars represent mean (SD)

significant difference was detected in triglycerides for any ketone supplement compared to control (Fig. 1b). MCT supplemented animals had a significant reduction in HDL blood levels compared to control $(\mathrm{p}<0.001)$ (Fig. 1c). LDL levels in ketone-supplemented animals did not significantly differ from controls (Fig. 1d).

\section{Ketone supplementation causes rapid and sustained elevation of $\beta \mathrm{HB}$}

Over the 28-day experiment, ketone supplements administered daily significantly elevated blood ketone levels without dietary restriction (Fig. 2a, b). Naturally derived ketogenic supplements including MCT $(5 \mathrm{~g} / \mathrm{kg})$ elicited a significant rapid elevation in blood $\beta \mathrm{HB}$ within 30-60 min that was sustained for $8 \mathrm{~h}$. BMS + MCT (5 g/ $\mathrm{kg}$ ) elicited a significant elevation in blood $\beta \mathrm{HB}$ at $4 \mathrm{~h}$, which was no longer significant at $8 \mathrm{~h}$. BMS $(5 \mathrm{~g} / \mathrm{kg})$ did not elicit a significant elevation in blood $\beta \mathrm{HB}$ at any time point. For days $14-28$, BMS + MCT $(10 \mathrm{~g} / \mathrm{kg})$ and MCT $(10 \mathrm{~g} / \mathrm{kg})$ elevated blood $\beta$ HB levels within $30 \mathrm{~min}$ and remained significantly elevated for up to $12 \mathrm{~h}$. We observed a delay in the peak elevation of blood $\beta \mathrm{HB}$ :
BMS + MCT peaked at $8 \mathrm{~h}$ instead of at $4 \mathrm{~h}$ and MCT at $4 \mathrm{~h}$ instead of at $1 \mathrm{~h}$. Blood $\beta \mathrm{HB}$ levels in the BMS group did not show significant elevation at any time point, even after dose escalation (Fig. 2a). Synthetically derived ketogenic supplements including $\mathrm{KE}$ and $\mathrm{BD}$ supplementation rapidly elevated blood $\beta \mathrm{HB}$ within $30 \mathrm{~min}$ and was sustained for $8 \mathrm{~h}$. For the rats receiving ketone supplementation in the form of $\mathrm{BD}$ or the $\mathrm{KE}$, dosage was kept at $5 \mathrm{~g} / \mathrm{kg}$ to prevent adverse effects associated with hyperketonemia. The Precision Xtra ${ }^{\mathrm{Tm}}$ ketone monitoring system measures $\beta \mathrm{HB}$ only; therefore, total blood ketone levels $(\beta \mathrm{HB}+\mathrm{AcAc})$ would be higher than measured. For each of these groups, the blood $\beta \mathrm{HB}$ profile remained consistent following daily ketone supplementation administration over the 4-week duration. (Fig. 2b).

\section{Ketone supplementation causes a significant decrease of blood glucose}

Administration of ketone supplementation significantly reduced blood glucose over the course of the study (Fig. 3a, b). MCT (5 g/kg) decreased blood glucose compared to control within $30 \mathrm{~min}$ which was sustained for 

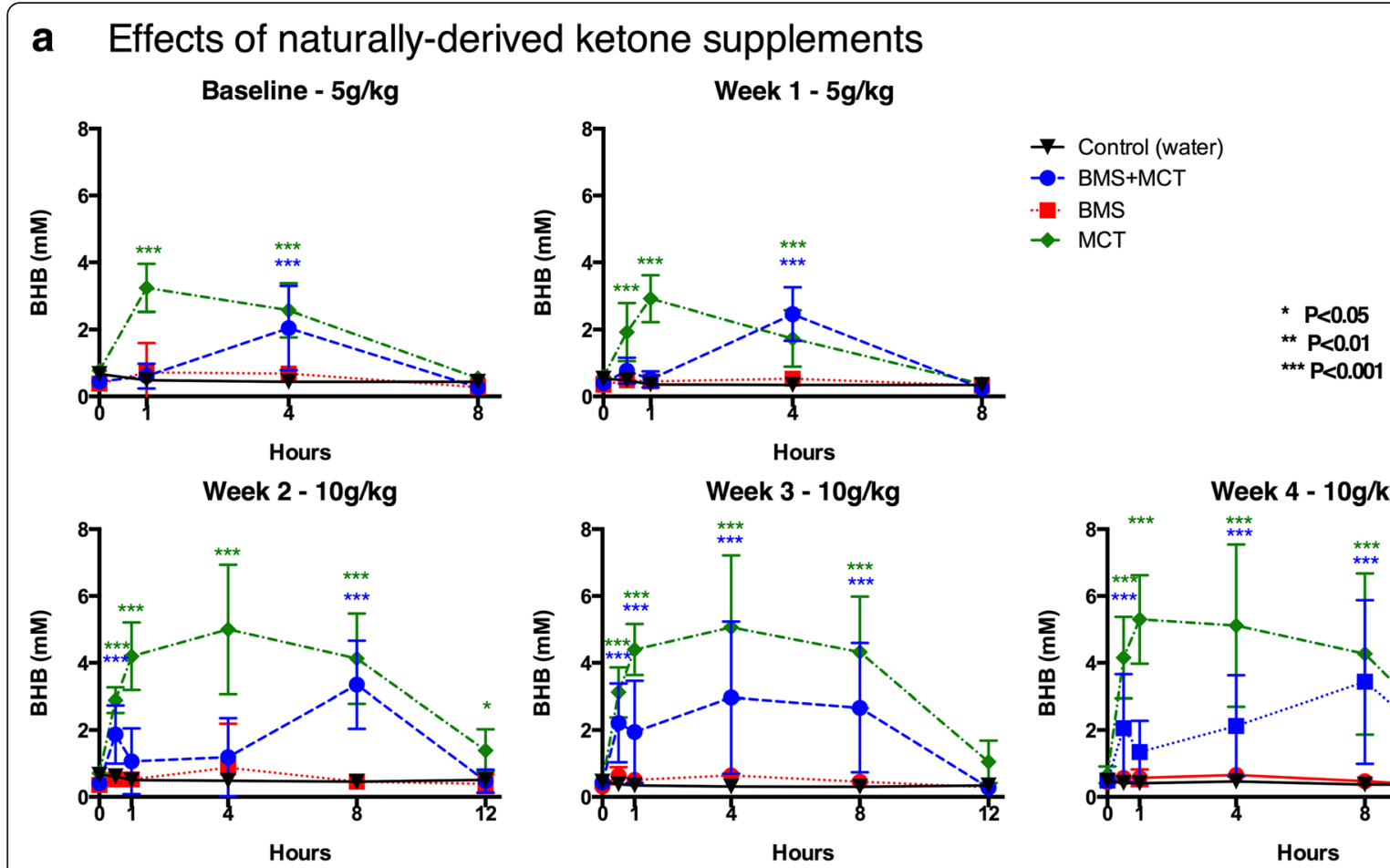

b Effects of synthetically-derived ketone supplements
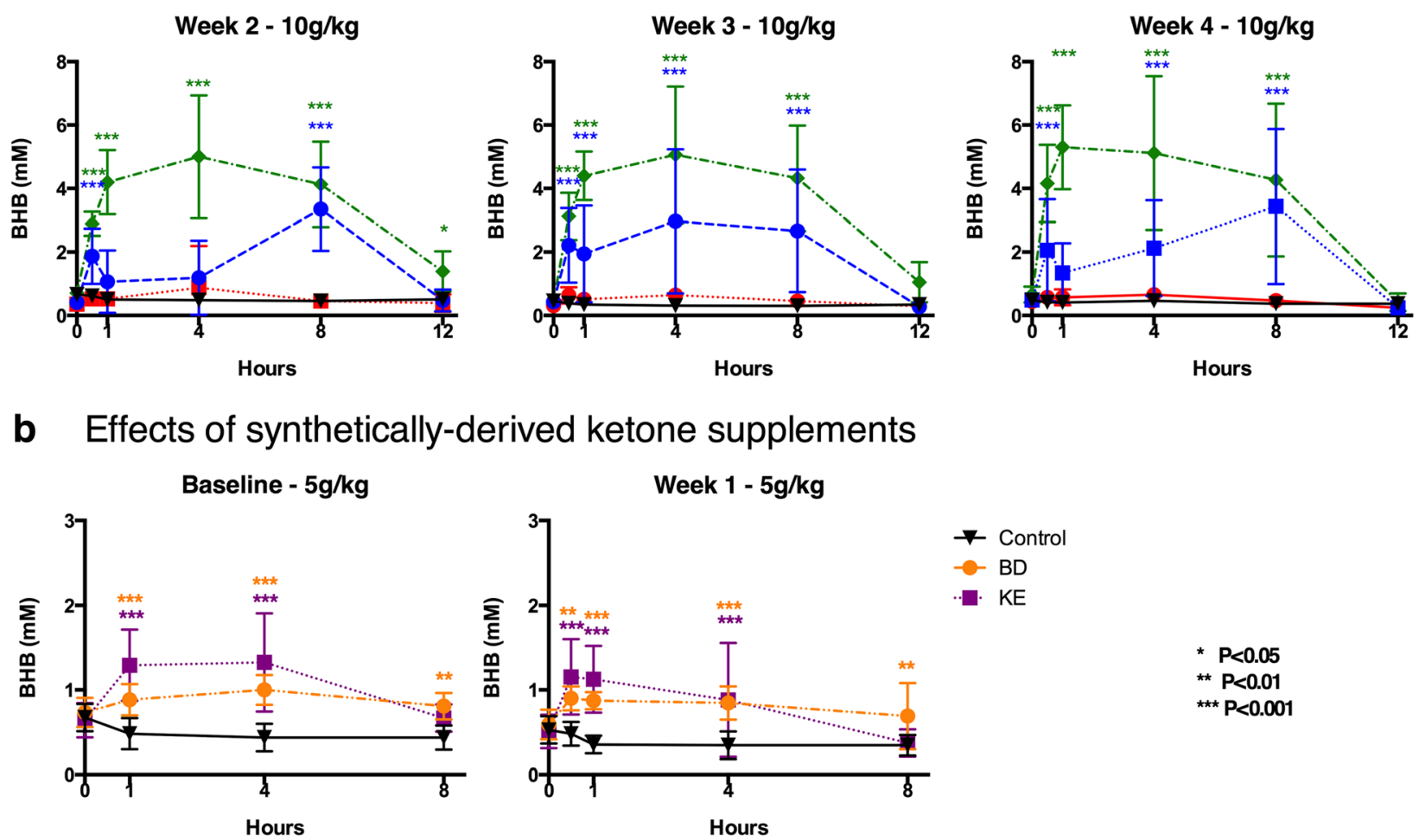

$$
\begin{aligned}
& \rightarrow \text { Control } \\
& - \text { BD } \\
& - \text { - KE }
\end{aligned}
$$
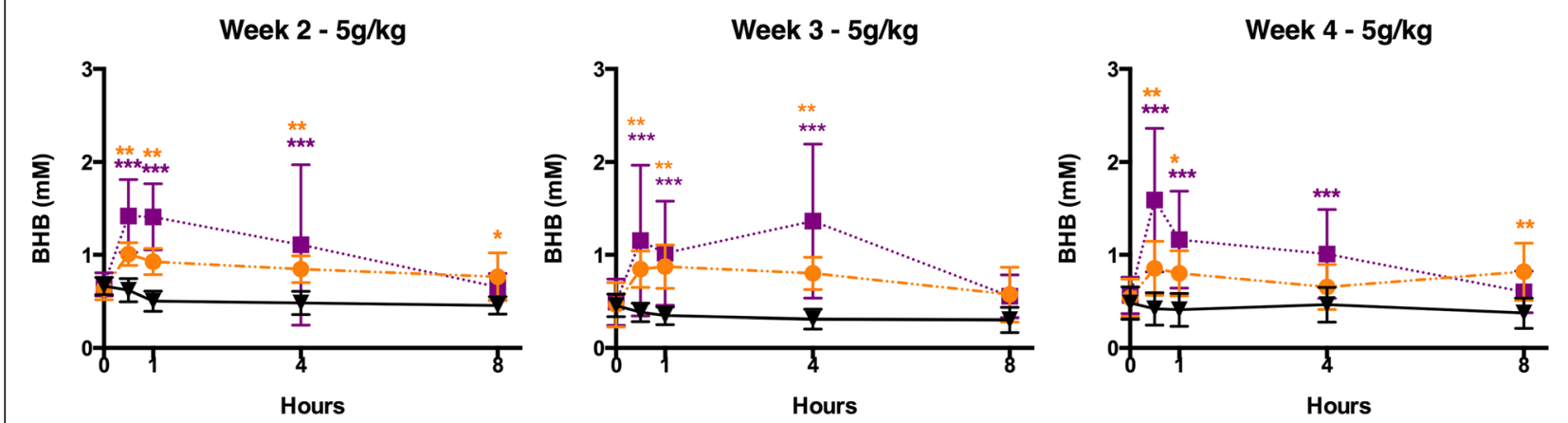

Fig. 2 Effects of ketone supplementation on blood $\beta H B$. $\mathbf{a}$, b Blood $\beta H B$ levels at times $0,0.5,1,4,8$, and 12 h post intragastric gavage for ketone supplements tested. a BMS + MCT and MCT supplementation rapidly elevated and sustained significant $\beta$ HB elevation compared to controls for the duration of the 4-week dose escalation study. BMS did not significantly elevate $\beta \mathrm{HB}$ at any time point tested compared to controls. $\mathbf{b}$ BD and KE supplements, maintained at $5 \mathrm{~g} / \mathrm{kg}$, significantly elevated $\beta \mathrm{HB}$ levels for the duration of the 4-week study. Two-Way ANOVA with Tukey's post hoc test, results considered significant if $p<0.05$. Error bars represent mean (SD) 


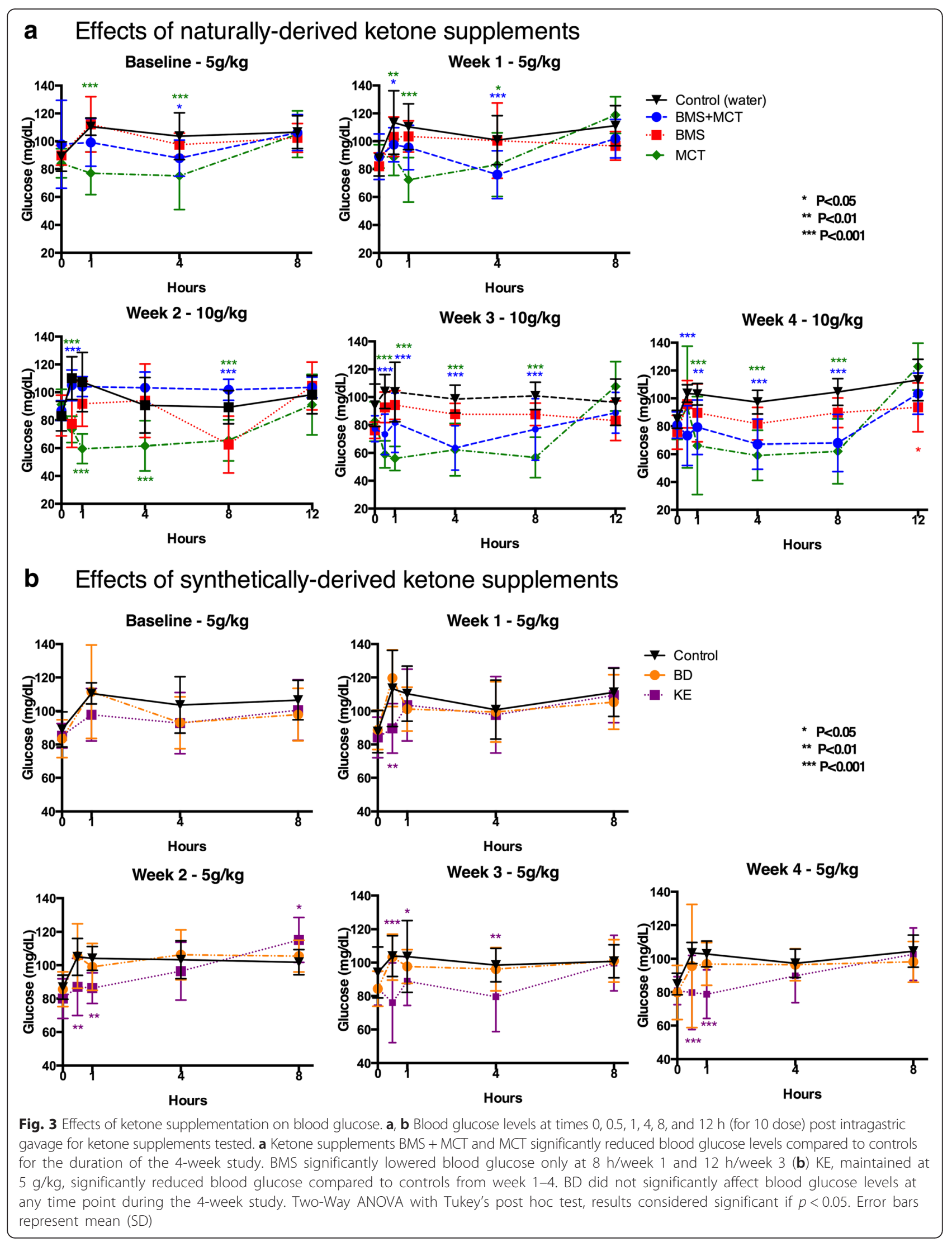


$8 \mathrm{~h}$ at baseline and at week 1 . MCT $(10 \mathrm{~g} / \mathrm{kg})$ likewise decreased blood glucose within $30 \mathrm{~min}$ and lasted through the $12 \mathrm{~h}$ time point during weeks 2,3 , and 4 . $\mathrm{BMS}+\mathrm{MCT}(5 \mathrm{~g} / \mathrm{kg})$ lowered blood glucose compared to control from hours $1-8$ only at week 1 . BMS + MCT $(10 \mathrm{~g} / \mathrm{kg})$ lowered blood glucose compared to control within $30 \mathrm{~min}$ and remained low through the $12 \mathrm{~h}$ time point at weeks 2, 3, and 4. Rats supplemented with BMS had lower blood glucose compared to control at $12 \mathrm{~h}$ in week 4 (10) (Fig. 3a). Administration of BD did not significantly change blood glucose levels at any time point during the 4-week study. KE $(5 \mathrm{~g} / \mathrm{kg})$ significantly lowered blood glucose levels at 30 min for week 1, 2, 3, and
4 and was sustained through $1 \mathrm{~h}$ at weeks $2-4$ and sustained to $4 \mathrm{~h}$ at week 3. (Fig. 3b).

\section{Hyperketonemia suppresses blood glucose levels}

At baseline, $4 \mathrm{~h}$ after intragastric gavage, the elevation of blood ketones was inversely related to the reduction of blood glucose compared to controls following the administration of MCT $(5 \mathrm{~g} / \mathrm{kg})(\mathrm{p}=0.008)$ and BMS + MCT $(5 \mathrm{~g} / \mathrm{kg})(\mathrm{p}=$ 0.039 ) . There was no significant correlation between blood ketone levels and blood glucose levels compared to controls for any other ketone supplemented group at baseline (Fig. 4a). At week 4, $4 \mathrm{~h}$ after intragastric gavage, there was a significant correlation between blood ketone levels and

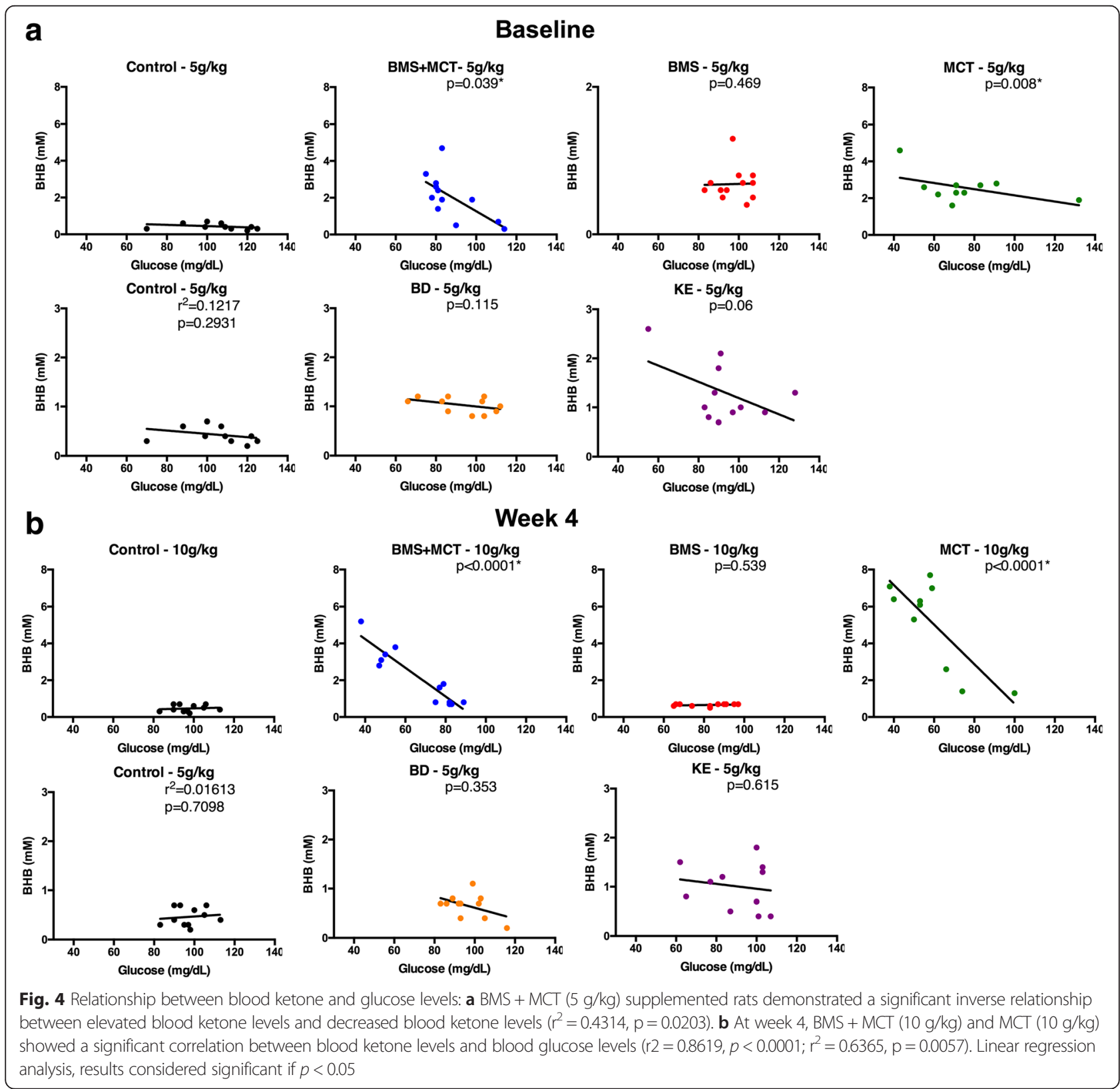


blood glucose levels compared to controls in MCT $(10 \mathrm{~g} / \mathrm{kg})$ and BMS + MCT $(10 \mathrm{~g} / \mathrm{kg})(p<0.0001, p<0.0001)$ (Fig. 4b).

\section{Ketone supplementation changes organ weight and decreases body weight}

At day 29 of the study, animals were euthanized and brain, lungs, liver, kidneys, spleen and heart were harvested and weighed. Organ weights were normalized to body weight. Ketone supplementation did not significantly change brain, lung, kidney, or heart weights compared to controls (Fig. 5a, b, d, f). MCT supplemented animals had significantly larger livers compared to their body weight $(p<0.05)$ (Fig. $5 \mathrm{c})$. Ketone supplements $\mathrm{BMS}+\mathrm{MCT}$, MCT and BD caused a significant reduction in spleen size (BMS + MCT $p<0.05$, MCT $p$ $<0.001, \mathrm{BD} p<0.05$ ) (Fig. 5e). Rats administered KE gained significantly less weight over the entire study compared to controls. BMS + MCT, BMS, and BD supplemented rats gained significantly less weight than controls during weeks $2-4$, and MCT animals gained less

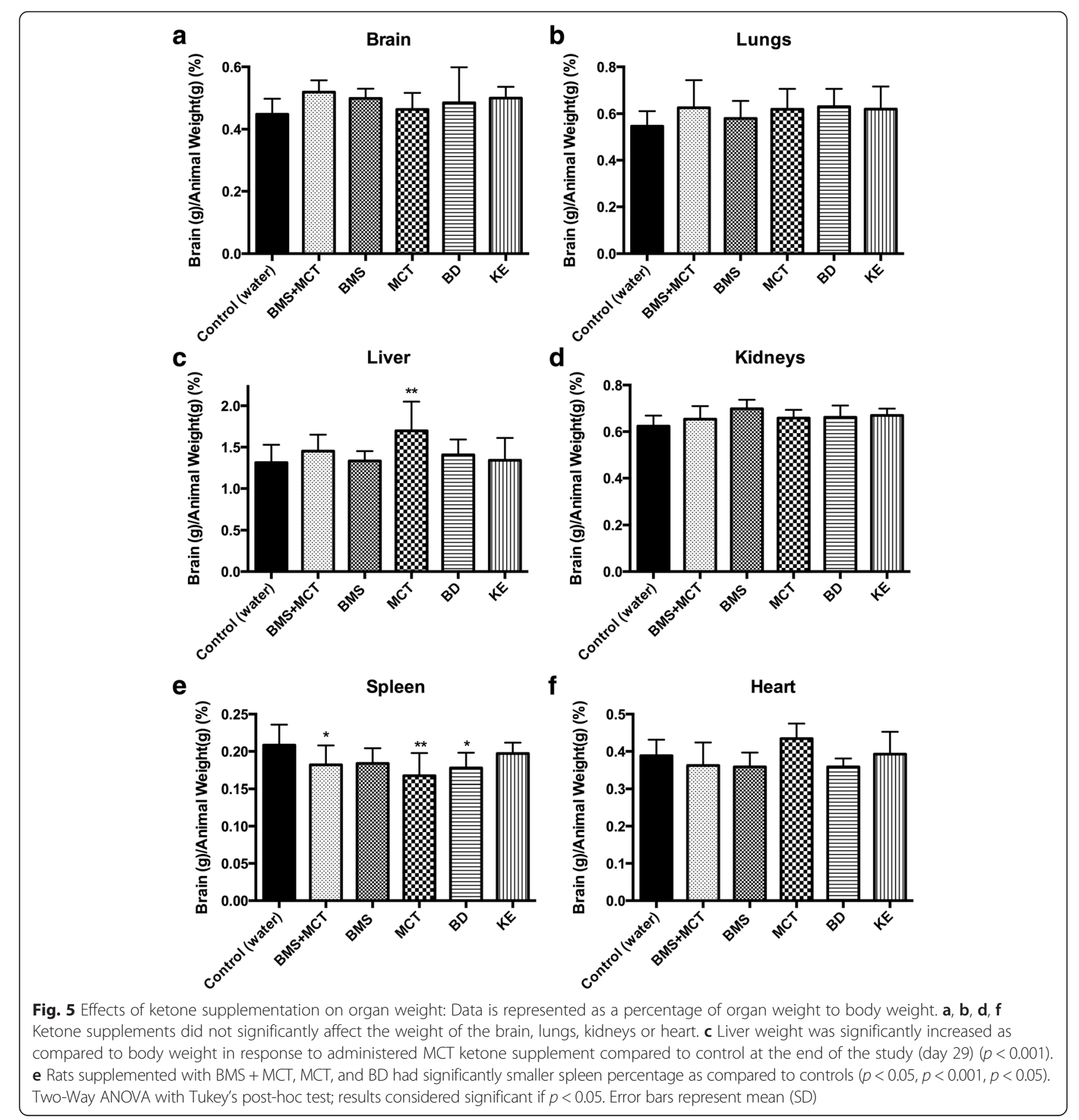


weight than controls at weeks $3-4$ (Fig. 6). Increased gastric motility (increased bowel evacuation and changes to fecal consistency) was visually observed in rats supplemented with $10 \mathrm{~g} / \mathrm{kg} \mathrm{MCT}$, most notably at the 8 and 12-h time points. All animals remained in healthy weight range for their age even though the rate of weight gain changed with ketone supplementation [53-54]. Food intake was not measured in this study. However, there was not a significant change in basal blood glucose or basal blood ketone levels over the 4 week study in any of the rats supplemented with ketones (Fig. 7).

\section{Discussion}

Nutritional ketosis induced with the KD has proven effective for the metabolic management of seizures and potentially other disorders [1-26]. Here we present evidence that chronic administration of ketone supplements can induce a state of nutritional ketosis without the need for dietary carbohydrate restriction and with little or no effect on lipid biomarkers. The notion that we can produce the therapeutic effects of the KD with exogenous ketone supplementation is supported by our previous study which demonstrated that acutely administered KE supplementation delays central nervous system (CNS) oxygen toxicity seizures without the need for dietary restriction [29]. We propose that exogenous ketone supplementation could provide an alternative method of attaining the therapeutic benefits of nutritional ketosis, and as a means to further augment the therapeutic potential of the KD.

\section{Ketone supplementation causes little to no change in triglycerides and lipoproteins}

One common concern regarding the KD is its purported potential to increase the risk of atherosclerosis by elevating blood cholesterol and triglyceride levels $[55,56]$. This topic remains controversial as some, but not all, studies have demonstrated that the KD elevates blood levels of cholesterol and triglycerides [57-62]. Kwitervich and colleagues demonstrated an increase in low-density lipoprotein (LDL) and a decrease in high-density lipoprotein (HDL) in epileptic children fed the classical KD for two years [27]. In this study, total cholesterol increased by $\sim 130 \%$, and stabilized at the elevated level over the 2-year period. A similar study demonstrated that the lipid profile returned to baseline in children who remained on the $\mathrm{KD}$ for six years [63]. Children typically remain on the diet for approximately two years then return to a diet of common fat and carbohydrate ingestion [64]. The implications of these findings are unclear, since the influence of cholesterol on cardiovascular health is controversial and macronutrient sources of the diet vary per study. In contrast to these studies, the majority of recent studies have suggested that the KD can actually lead to significant benefits in biomarkers of metabolic health, including blood lipid profiles [65-72]. In these studies, the

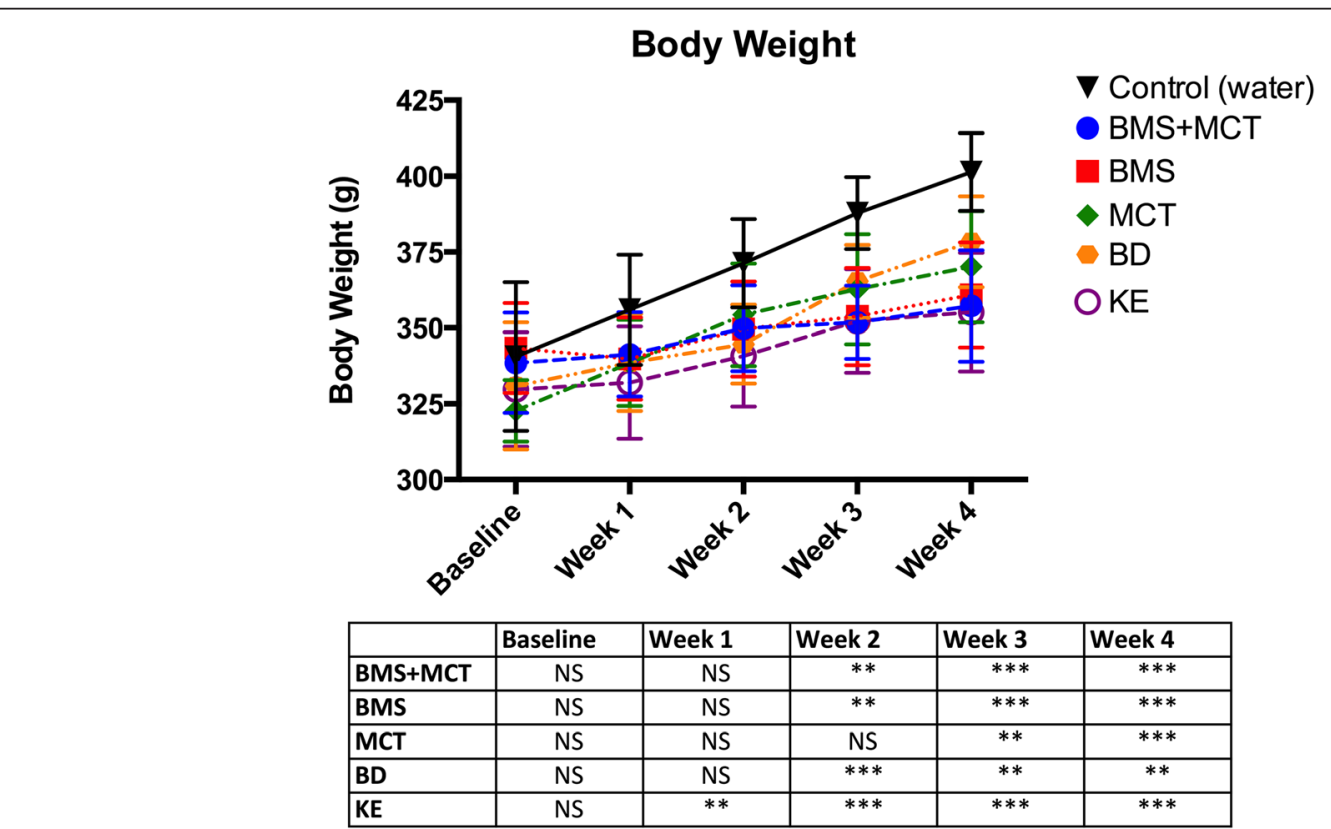

Fig. 6 Effects of ketone supplementation on body weight: Rats administered ketone supplements gained less weight over the 4-week period; however, did not lose weight and maintained healthy range for age. KE supplemented rats gained significantly less weight during the entire 4-week study compared to controls. BMS + MCT, BMS, and BD supplemented rats gained significantly less weight than controls over weeks 2-4.MCT supplemented rats gained significantly less weight than controls over weeks 3-4, Two-Way ANOVA with Tukey's post hoc test, results considered significant if $p<0.05$. Error bars represent mean (SD) 


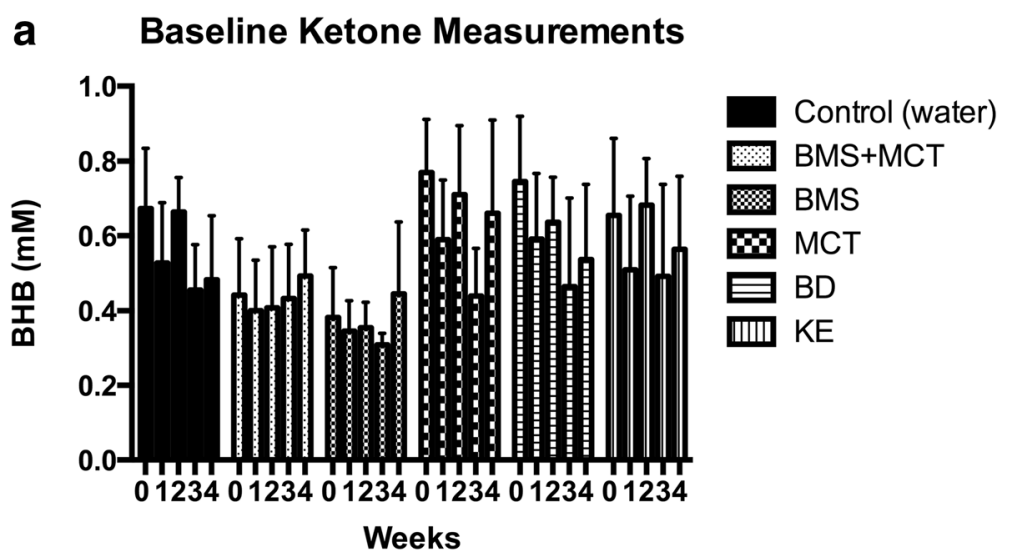

\section{b Baseline Glucose Measurements}

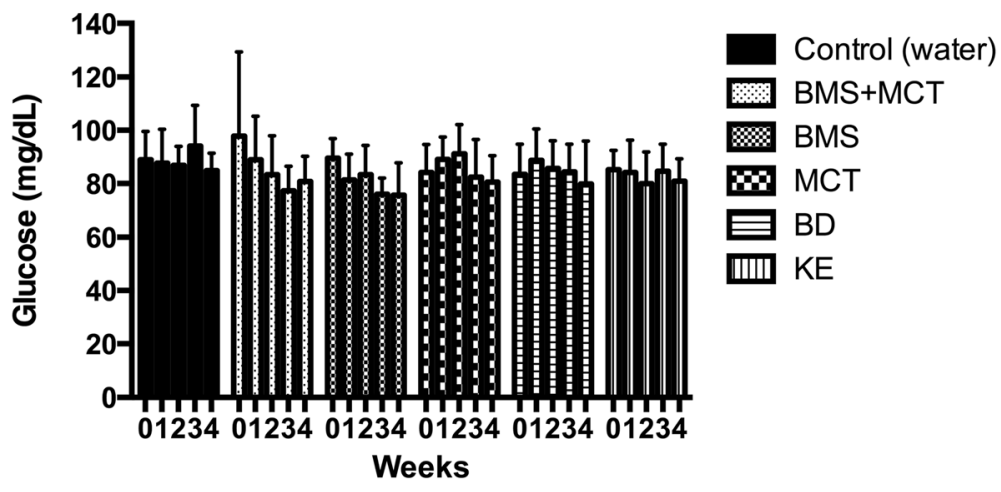

Fig. 7 Effects of ketone supplementation on basal blood ketone and basal blood glucose levels: Rats administered ketone supplements did not have a significant change in basal blood ketone levels (a) or basal blood glucose levels (b) for the four week study. Two-Way ANOVA with Tukey's post-hoc test, results considered significant if $p<0.05$. Error bars represent mean (SD)

KD positively altered blood lipids, decreasing total triglycerides and cholesterol while increasing the ratio of HDL to LDL [68-77]. Although, the KD is well-established in children, it has only recently been utilized as a strategy to control seizures in adults. In 2014, Schoeler and colleagues reported on the feasibility of the KD for adults, concluding that $39 \%$ of individuals achieved $>50 \%$ reduction in seizure frequency, similar to the results reported in pediatric studies. Patients experienced similar gastrointestinal adverse advents that have been previously described in pediatric patients, but they did not lead to discontinuation of the diet in any patient [78].

With oral ketone supplementation, we observed a significant elevation in blood $\beta \mathrm{HB}$ without dietary restriction and with little change in lipid biomarkers (Fig. 1). Over the 4 week study, MCT-supplemented rats demonstrated decreased HDL compared to controls. No significant changes were observed in any of the triglycerides or lipoproteins (HDL, LDL) with any of the remaining exogenously applied ketone supplements. It should be noted that the rats used for this study had not yet reached full adult body size [79]. Their normal growth rate and maturation was likely responsible for the changes in triglyceride and lipoprotein levels observed in the control animals over the 4 week study (baseline data not shown, no significant differences) [80, 81]. Future studies are needed to investigate the effect of ketone supplementation on fully mature and aged animals. Overall, our study suggests that oral ketone supplementation has little effect on the triglyceride or lipoprotein profile after 4 weeks. However, it is currently unknown if ketone supplementation would affect lipid biomarkers after a longer duration of consumption. Further studies are needed to determine the effects of ketone supplements on blood triglyceride and lipoproteins after chronic administration and as a means to further enhance the hyperketonemia and improve the lipid profile of the clinically implemented (4:1) KD.

LDL is the lipoprotein particle that is most often associated with atherosclerosis. LDL particles exist in different sizes: large molecules (Pattern A) or small molecules (Pattern B). Recent studies have investigated the importance of LDL-particle type and size rather than total concentration as being the source for cardiovascular risk [56]. Patients whose LDL particles are predominantly small and dense (Pattern B) have a greater risk of 
cardiovascular disease (CVD). It is thought that small, dense LDL particles are more able to penetrate the endothelium and cause in damage and inflammation [82-85]. Volek et al. reported that the KD increased the pattern and volume of LDL particles, which is considered to reduce cardiovascular risk [73]. Though we did not show a significant effect on LDL levels for ketone supplements, future chronic feeding studies will investigate the effects of ketone supplementation on lipidomic profile and LDL particle type and size.

\section{Therapeutic levels of hyperketonemia suppress blood glucose levels}

We demonstrated that therapeutic ketosis could be induced without dietary (calorie or carbohydrate) restriction and that this acute elevation in blood ketones was significantly correlated with a reduction in blood glucose (Figs. 2, 3 and 4). The BMS ketone supplement did not significantly induce blood hyperketonemia or reduced glucose in the rats. The KE supplemented rats trended towards reduced glucose levels; however, the lower dose of this agent did not lower glucose significantly, as reported previously in acute response of mice [59]. MCTs have previously been shown to elicit a slight hypoglycemic effect by enhancing glucose utilization in both diabetic and non-diabetic patients [86-88]. Kashiwaya et al. demonstrated that both blood glucose and blood insulin decreased by approximately $50 \%$ in rats fed a diet where $30 \%$ of calories from starch were replaced with ketone esters for 14 days, suggesting that ketone supplementation increases insulin sensitivity or reduced hepatic glucose output [89]. This ketone-induced hypoglycemic effect has been previously reported in humans with IV infusions of ketone bodies [90, 91]. Recently, Mikkelsen et al. showed that a small increase in $\beta \mathrm{HB}$ concentration decreases glucose production by $14 \%$ in post-absorptive health males [92]. However, this has not been previously reported with any of the oral exogenous ketone supplements we studied. Ketones are an efficient and sufficient energy substrate for the brain, and will therefore prevent side effects of hypoglycemia when blood levels are elevated and the patient is keto-adapted. This was most famously demonstrated by Owen et al. in 1967 wherein keto-adapted patients (starvation induced therapeutic ketosis) were given 20 IU of insulin. The blood glucose of fasted patients dropped to $1-2 \mathrm{mM}$, but they exhibited no hypoglycemic symptoms due to brain utilization of ketones for energy [93]. Therefore, ketones maintain brain metabolism and are neuroprotective during severe hypoglycemia. The rats in the MCT group had a correlation of blood ketone and glucose levels at week 4, whereas the combination of BMS + MCT produced a significant hypoglycemic correlation both at baseline and at week 4 . No hypoglycemic symptoms were observed in the rats during this study. Insulin levels were not measured in this study; however, future ketone supplementation studies should measure the effects of exogenous ketones on insulin sensitivity with a glucose tolerance test. An increase in insulin sensitivity in combination with our observed hypoglycemic effect has potential therapy implications for glycemic control in T2D [40]. Furthermore, it should be noted that the KE metabolizes to both AcAc and $\beta \mathrm{HB}$ in 1:1 ratio [29]. The ketone monitor used in this study only measures $\beta \mathrm{HB}$ as levels of AcAc are more difficult to measure due to spontaneous decarboxylation to acetone; therefore, the total ketone levels $(\beta \mathrm{HB}+\mathrm{AcAc})$ measured were likely higher, specifically for the KE [14]. Interestingly, the $10 \mathrm{~g} / \mathrm{kg}$ dose produced a delayed blood $\beta \mathrm{HB}$ peak for ketone supplements MCT and BMS + MCT. The higher dose of the ketogenic supplements elevated blood levels more substantially, and thus reached their maximum blood concentration later due to prolonged metabolic clearance. It must be noted that the dosage used in this study does not translate to human patients, since the metabolic physiology of rats is considerably higher. Future studies will be needed to determine optimal dosing for human patients.

\section{Effects of ketone supplementation on organ weight and body weight percentage}

Ketone supplementation did not affect the size of the brain, lungs, kidneys or heart of rats. As previously mentioned, the rats were still growing during the experimental time frame; therefore, organ weights were normalized to body weight to determine if organ weight changed independently to growth. There could be several reasons why ketones influenced liver and spleen weight. The ratio of liver to body weight was significantly higher in the MCT supplemented animals (Fig. 5). MCTs are readily absorbed in the intestinal lumen and transported directly to the liver via hepatic portal circulation. When given a large bolus, such as in this study, the amount of MCTs in the liver will likely exceed the $\beta$-oxidation rate, causing the MCTs to be deposited in the liver as fat droplets [94]. The accumulated MCT droplets in the liver could explain the higher liver weight to body weight percentage observed with MCT supplemented rats. Future toxicology and histological studies will be needed to determine the cause of the observed hepatomegaly. It should be emphasized that the dose in this study is not optimized in humans. We speculate that an optimized human dose would be lower and may not cause hepatomegaly or potential fat accumulation. Nutritional ketosis achieved with the KD has been shown to decrease inflammatory markers such as TNF- $\alpha$, IL-6, IL-8, MCP-1, E-selectin, I-CAM, and PAI-1 [8, 46], which may account for the observed decrease in spleen weight. As previously mentioned, Veech and colleagues demonstrated that exogenous 
supplementation of $5 \mathrm{mM} \beta \mathrm{HB}$ resulted in a $28 \%$ increase in hydraulic work in the working perfused rat heart and a significant decrease in oxygen consumption [28, 41, 42]. Ketone bodies have been shown to increase cerebral blood flow and perfusion [95]. Also, ketone bodies have been shown to increase ATP synthesis and enhance the efficiency of ATP production [14, 28, 40]. It is possible that sustained ketosis results in enhanced cardiac efficiency and $\mathrm{O}_{2}$ consumption. Even though the size of the heart did not change for any of the ketone supplements, further analysis of tissues harvested from the ketone-supplemented rats will be needed to determine any morphological changes and to understand changes in organ size. It should be noted that the Harlan standard rodent chow 2018 is nutritionally complete and formulated with high-quality ingredients to optimize gestation, lactation, growth, and overall health of the animals. The same cannot be said for the standard American diet (SAD). Therefore, we plan to investigate the effects of ketone supplements administered with the SAD to determine if similar effects will be seen when the micronutrient deficiencies and macronutrient profile mimics what most Americans consume.

MCT oil has recently been used to induce nutritional ketosis although it produces dose-dependent gastrointestinal (GI) side effects in humans that limit the potential for its use to significantly elevate ketones $(>0.5 \mathrm{mM})$. Despite these limitations, Azzam and colleagues published a case report in which a 43-year-old-man had a significant decrease in seizure frequency after supplementing his diet with 4 tablespoons of MCT oil twice daily [96]. An attempt to increase his dosage to 5 tablespoons twice daily was halted by severe GI intolerance. Henderson et al. observed that $20 \%$ of patients reported GI side effects with a $20 \mathrm{~g}$ dose of ketogenic agent AC-1202 in a double blind trial in mild to moderate Alzheimer's patients [24]. We visually observed similar gastrointestinal side effects (loose stools) in the rats treated with MCT oil in our study. Rats were closely monitored to avoid dehydration, and gastric motility returned to normal between $12-24 \mathrm{~h}$. Interestingly, the BMS + MCT supplement elevated $\beta \mathrm{HB}$ similarly to MCT oil alone, without causing the adverse gastrointestinal effects seen in MCT-supplemented rats. However, this could be due to the fact in a $10 \mathrm{~g} / \mathrm{kg}$ dose of BMS + MCT, only $5 \mathrm{~g} /$ $\mathrm{kg}$ is MCT alone, which is less than the $10 \mathrm{~g} / \mathrm{kg}$ dose that elicits the GI side effects. This suggests that this novel combination may provide a more useful therapeutic option than MCT oil alone, which is limited in its ability to elevate ketones in humans.

Exogenously delivered ketone supplements significantly altered rat weight gain for the duration of the study (Fig. 6). However, rats did not lose weight and maintained a healthy range for their age. Rats have been shown to effectively balance their caloric intake to prevent weight loss/gain [97-99]. Due to the caloric density of the exogenous ketone supplements (Table 1) it is possible for the rats to eat less of the standard rodent chow and therefore less carbohydrates while maintaining their caloric intake. Food intake was not measured for this study. However, if there was a significant carbohydrate restriction there would be a signifcant change in basal blood ketone and blood glucose levels. As the hallmark to the KD, carbohydrate restriction increases blood ketone levels and reduces blood glucose levels. Neither an increase in basal blood ketone levels nor a decrease in basal blood glucose levels was observed in this study (Fig. 7). Additionally, if there were an overall blood glucose decrease due to a change in food intake, this would not explain the rapid reduction (within $30 \mathrm{~min}$ ) in blood glucose correlated with an elevation of blood ketone levels after an intragastric bolus of ketone supplement (Figs. 2, 3 and 4).

\section{Conclusions}

Several studies have investigated the safety and efficacy of ketone supplements for disease states such as AD and Parkinson's disease, and well as for parenteral nutrition [40, 48-50, 100-103]. Our research demonstrates that several forms of dietary ketone supplementation can effectively elevate blood ketone levels and achieve deleted: therapeutic nutritional ketosis without the need for dietary carbohydrate restriction. We also demonstrated that ketosis achieved with exogenous ketone supplementation can reduce blood glucose, and this is inversely associated with the blood ketone levels. Although preliminary results are encouraging, further studies are needed to determine if oral ketone supplementation can produce the same therapeutic benefits as the classic KD in the broadspectrum of KD-responsive disease states . Additionally, further experiments need to be conducted to see if the exogenous ketone supplementation affects the same physiological features as the KD (i.e. ROS, inflammation, ATP production). Ketone supplementation could be used as an alternative method for inducing ketosis in patients uninterested in attempting the KD or those who have previously had difficulty implementing the $\mathrm{KD}$ because of palatability issues, gall bladder removal, liver abnormalities, or intolerance to fat. Additional experiments should be conducted to see if ketone supplementation could be used in conjunction with the KD to assist and ease the transition to nutrition ketosis and enhance the speed of keto-adaptation. In this study we have demonstrated the ability of several ketone supplements to elevate blood ketone levels, providing multiple options to induce therapeutic ketosis based on patient need. Though additional studies are needed to determine the therapeutic potential of ketone supplementation, many patients that previously 
were unable to benefit from the KD may now have an alternate method of achieving therapeutic ketosis. Ketone supplementation may also represent a means to further augment ketonemia in those responsive to therapeutic ketosis, especially in those individuals where maintaining low glucose is important.

\section{Abbreviations}

ACAc: acetoacetate; ALS: amyotrophic lateral sclerosis; AD: Alzheimer's; BHB: beta-hydroxybutyrate; BMS: sodium/potassium $\beta \mathrm{HB}$ mineral salt; BMS + MCT: BMS + MCT 1:1 mixture; BD: 1,3-butanediol; CNS: central nervous system; HDL: high density lipoprotein; HDACs: histone deacetylases; LDL: low density lipoprotein; KD: ketogenic diet; KE: 1, 3-butanediol acetoacetate diester/ketone ester; MCT: medium chain triglyceride oil; PCOS: polycystic ovary syndrome; ROS: reactive oxygen species; SAD: standard American diet; TBI: traumatic brain injury; T2D: type-2 diabetes.

\section{Competing interests}

International Patent \# PCT/US2014/031237, University of South Florida, D.P. D'Agostino, S. Kesl, P. Arnold, "Compositions and Methods for Producing Elevated and Sustained Ketosis". P. Arnold (Savind) has received financial support (ONR N000140610105 and N000140910244) from D.P. D'Agostino (USF) to synthesize ketone esters. The remaining authors have no conflicts of interest.

\section{Authors' contributions}

Conceived and designed the experiments: SK, AP, NW, TF, DP. Performed the experiments: SK, AP, NW, TF, CA, JS, AVP. Analyzed the data: SK, AP, DP. Contributed reagents/materials/analysis tools: PA. Helped draft the manuscript: SK, AP, NW, CA, DP. All authors read and approved the final manuscript.

\section{Acknowledgements}

The authors would like to thank Savind Inc for manufacturing some of the ketone supplements, Jay Dean for the use of his Hyperbaric Research Laboratory, and the ONR and Scivation Inc. for funding the project.

\section{Grants}

This study was supported by the Office of Naval Research (ONR) Grant N000140610105 (DPD); and a Morsani College of Medicine Department of Molecular Pharmacology and Physiology departmental grant.

\section{Author details}

${ }^{1}$ Department of Molecular Pharmacology and Physiology, Morsani College of Medicine, University of South Florida, 12901 Bruce B. Downs Blvd. MDC8, Tampa, FL 33612, USA. ${ }^{2}$ Savind Inc, 205 South Main Street, Seymore, IL 61875, USA

Received: 10 September 2015 Accepted: 28 January 2016

Published online: 04 February 2016

\section{References}

1. Sirven J, Whedon B, Caplan D, Liporace J, Glosser D, O'Dwyer J, et al. The ketogenic diet for intractable epilepsy in adults: preliminary results. Epilepsia. 1999;40(12):1721-6. doi:10.1111/j.1528-1157.1999.tb01589.x.

2. Wilder R. The effect of ketonemia on the course of epilepsy. Mayo Clin Bulletin. 1921;2:307-8.

3. Thiele E. Assessing the efficacy of antiepileptic treatments: the ketogenic diet. Epilepsia. 2003;44 Suppl 7:26-9. doi:10.1046/j.1528-1157.44.s7.4.x.

4. Paoli A, Rubini A, Volek JS, Grimaldi KA. Beyond weight loss: a review of the therapeutic uses of very-low-carbohydrate (ketogenic) diets. Eur J Clin Nutr. 2013;67(8):789-96. doi:10.1038/ejcn.2013.116.

5. Foster GD, Wyatt HR, Hill JO, McGuckin BG, Brill C, Mohemmed BS, et al. A randomized trial of a low-carbohydrate diet for obesity. N Engl J Med. 2003; 348:2082-90.

6. Westman EC, Feinman RD, Mavropoulos JC, Vernon MC, Volek JS, Wortman JA, et al. Low-carbohydrate nutrition and metabolism. Am J Clin Nutr. 2007; $86: 276-84$.
7. Westman EC, Yancy WS, Edman JS, Tomlin KF, Perkins CE. Effect of 6-month adherence to a very low carbohydrate diet program. Am J Med. 2002; 113(1):30-6.

8. Forsythe C, Phinney S, Fernandez M, Quann E, Wood R, Bibus D, et al. Comparison of low fat and low carbohydrate diets on circulating fatty acid composition and markers of inflammation. Lipids. 2008;43(1):65-77. doi:10. 1007/s11745-007-3132-7.

9. Boden G, Sargrad K, Homko C, Mozzoli M, Stein T. Effect of a lowcarbohydrate diet on appetite, blood glucose levels, and insulin resistance in obese patients with type 2 diabetes. Ann Intern Med. 2005;142(6):403-11.

10. Gumbiner B, Wendel J, McDermott M. Effects of diet composition and ketosis on glycemia during very-low-energy-diet therapy in obese patients with non-insulin-dependent diabetes mellitus. Am J Clin Nutr. 1996;63(1):110-5.

11. Nielsen J, Joensson E. Low-carbohydrate diet in type 2 diabetes: stable improvement of bodyweight and glycemic control during 44 months follow-up. Nutr Metab. 2008:5:14. doi:10.1186/1743-7075-5-14

12. Yancy W, Foy M, Chalecki A, Vernon M, Westman E. A low-carbohydrate, ketogenic diet to treat type 2 diabetes. Nutr Metab. 2005;2:34. doi:10.1186/ 1743-7075-2-34.

13. Dashti HM, Al-Zaid NS, Mathew TC, Al-Mousawi M, Talib H, Asfar SK, et al. Long term effects of ketogenic diet in obese subjects with high cholesterol level. Mol Cell Biochem. 2006;286(1-2):1-9. doi:10.1007/s11010-005-9001-x.

14. Maalouf M, Rho JM, Mattson MP. The neuroprotective properties of calorie restriction, the ketogenic diet, and ketone bodies. Brain Res Rev. 2009;59(2): 293-315. doi:10.1016/j.brainresrev.2008.09.002.

15. Mavropoulos JC, Yancy WS, Hepburn J, Westman EC. The effects of a low-carbohydrate, ketogenic diet on the polycystic ovary syndrome: a pilot study. Nutr Metab. 2004;2:35. doi:10.1186/1743-7075-2-35.

16. Seyfried T, Flores R, Poff A, D'Agostino D. Cancer as a metabolic disease: implications for novel therapeutics. Carcinogenesis. 2014;35:515-27. doi:10. 1093/carcin/bgt480.

17. Poff AM, Ari C, Arnold P, Seyfried TN, D'Agostino DP. Ketone supplementation decreases tumor cell viability and prolongs survival of mice with metastatic cancer. Int J Cancer. 2014;135:1711-20. doi:10.1002/ijc.28809.

18. Poff A, Ari C, Seyfried T, D'Agostino D. The ketogenic diet and hyperbaric oxygen therapy prolong survival in mice with systemic metastatic cancer. PLoS ONE. 2013:8(6), e65522. doi:10.1371/journal.pone.0065522.

19. Seyfried T, Shelton L. Cancer as a metabolic disease. Nutr Metab. 2010;7:7. doi:10.1186/1743-7075-7-7.

20. Fine E, Segal-Isaacson C, Feinman R, Herszkopf S, Romano M, Tomuta N, et al. Targeting insulin inhibition as a metabolic therapy in advanced cancer: a pilot safety and feasibility dietary trial in 10 patients. Nutrition. 2012;28(10):1028-35. doi:10.1016/j.nut.2012.05.001.

21. Zhao Z, Lange D, Voustianiouk A, MacGrogan D, Ho L, Suh J, et al. A ketogenic diet as a potential novel therapeutic intervention in amyotrophic lateral sclerosis. BMC Neurosci. 2006;7:29. doi:10.1186/1471-2202-7-29.

22. White $H$, Venkatesh B. Clinical review: ketones and brain injury. Crit Care. 2011;15(2):219. doi:10.1186/cc10020.

23. Prins M. Cerebral metabolic adaptation and ketone metabolism after brain injury. J Cereb Blood Flow Metab. 2008;28(1):1-16. doi:10.1038/sj.jcbfm.9600543.

24. Henderson S, Vogel J, Barr L, Garvin F, Jones J, Costantini L. Study of the ketogenic agent AC-1202 in mild to moderate Alzheimer's disease: a randomized, double-blind, placebo-controlled, multicenter trial. Nutr Metab. 2009:6:31. doi:10.1186/1743-7075-6-31.

25. Brownlow M, Benner L, D'Agostino D, Gordon M, Morgan D. Ketogenic diet improves motor performance but not cognition in two mouse models of Alzheimer's pathology. PLoS ONE. 2013;8(9), e75713. doi:10.1371/journal. pone.0075713.g008

26. Kossoff EH, Hartman AL. Ketogenic diets: new advances for metabolism-based therapies. Curr Opin Neurol. 2012;25:173-8. doi:10.1097/WCO.0b013e3283515e4a.

27. Kwiterovich P, Vining E, Pyzik P, Skolasky R, Freeman J. Effect of a high-fat ketogenic diet on plasma levels of lipids, lipoproteins, and apolipoproteins in children. JAMA. 2003:290(7):912-20. doi:10.1001/jama.290.7.912.

28. Veech RL, Chance B, Kashiwaya Y, Lardy HA, Cahill Jr GF. Ketone bodies, potential therapeutic uses. IUBMB Life. 2001:51(4):241-7. doi:10.1080/ 152165401753311780

29. D'Agostino D, Pilla R, Held H, Landon C, Puchowicz M, Brunengraber H, et al. Therapeutic ketosis with ketone ester delays central nervous system oxygen toxicity seizures in rats. Am J Physiol Regul Integr Comp Physiol. 2013;304(10):R829-36. doi:10.1152/ajpregu.00506.2012. 
30. Gasior M, French A, Joy M, Tang R, Hartman A, Rogawski M. The anticonvulsant activity of acetone, the major ketone body in the ketogenic diet, is not dependent on its metabolites acetol, 1,2-propanediol, methylglyoxal, or pyruvic acid. Epilepsia. 2007;48(4):793-800. doi:10.1111/j.1528-1167.2007.01026.x.

31. Likhodii S, Nylen K, Burnham W. Acetone as an anticonvulsant. Epilepsia. 2008:49 Suppl 8:83-6. doi:10.1111/j.1528-1167.2008.01844.x.

32. Seymour K, Bluml S, Sutherling J, Sutherling W, Ross B. Identification of cerebral acetone by $1 \mathrm{H}-\mathrm{MRS}$ in patients with epilepsy controlled by ketogenic diet. Magma. 1999;8(1):33-42.

33. Halevy A, Peleg-Weiss L, Cohen R, Shuper A. An update on the ketogenic diet, 2012. Rambam Maimonides Med J. 2012;3(1), e0005. doi:10.5041/RMMJ. 10072.

34. Amari A, Grace N, Fisher W. Achieving and maintaining compliance with the ketogenic diet. J Appl Behav Anal. 1995;28(3):341-2. doi:10.1901/jaba. 1995.28-341.

35. Zhang $Y$, Kuang Y, LaManna J, Puchowicz M. Contribution of brain glucose and ketone bodies to oxidative metabolism. Adv Exp Med Biol. 2013;765: 365-70. doi:10.1007/978-1-4614-4989-8_51.

36. Maalouf M, Sullivan P, Davis L, Kim D, Rho J. Ketones inhibit mitochondrial production of reactive oxygen species production following glutamate excitotoxicity by increasing NADH oxidation. Neuroscience. 2007;145(1): 256-64. doi:10.1016/j.neuroscience.2006.11.065.

37. Milder J, Patel M. Modulation of oxidative stress and mitochondrial function by the ketogenic diet. Epilepsy Res. 2012;100(3):295-303. doi:10.1016/j. eplepsyres.2011.09.021

38. Shimazu T, Hirschey M, Newman J, He W, Shirakawa K, Le Moan N, et al. Suppression of oxidative stress by $\beta$-hydroxybutyrate, an endogenous histone deacetylase inhibitor. Science. 2013;339:211-4. doi:10.1126/science.1227166.

39. Kim DY, Davis L, Sullivan P, Maalouf M, Simeone T, van Brederode J, et al. Ketone bodies are protective against oxidative stress in neocortical neurons. J Neurochem. 2007;101(5):1316-26. doi:10.1111/j.1471-4159.2007.04483.x.

40. Veech $\mathrm{R}$. The therapeutic implications of ketone bodies: the effects of ketone bodies in pathological conditions: ketosis, ketogenic diet, redox states, insulin resistance, and mitochondrial metabolism. Prostaglandins Leukot Essent Fat Acids. 2004;70(3):309-19. doi:10.1016/j.plefa.2003.09.007.

41. Sato K, Kashiwaya Y, Keon C, Tsuchiya N, King M, Radda G, et al. Insulin, ketone bodies, and mitochondrial energy transduction. FASEB J. 1995;9(8):651-8.

42. Kashiwaya $Y$, Sato K, Tsuchiya N, Thomas S, Fell D, Veech R, et al. Control of glucose utilization in working perfused rat heart. J Biol Chem. 1994;269(41): 25502-14.

43. Sullivan P, Rippy N, Dorenbos K, Concepcion R, Agarwal A, Rho J. The ketogenic diet increases mitochondrial uncoupling protein levels and activity. Ann Neurol. 2004;55(4):576-80. doi:10.1002/ana.20062.

44. Bough K, Rho J. Anticonvulsant mechanisms of the ketogenic diet. Epilepsia. 2007;48(1):43-58. doi:10.1111/j.1528-1167.2007.00915.x.

45. Bough K, Wetherington J, Hassel B, Pare J, Gawryluk J, Greene J, et al. Mitochondrial biogenesis in the anticonvulsant mechanism of the ketogenic diet. Ann Neurol. 2006;60(2):223-35. doi:10.1002/ana.20899.

46. Ruskin D, Kawamura M, Masino S. Reduced pain and inflammation in juvenile and adult rats fed a ketogenic diet. PLoS ONE. 2009;4(12), e8349. doi:10.1371/journal.pone.0008349.

47. Paoli A, Moro T, Bosco G, Bianco A, Grimaldi KA, Camporesi E, et al. Effects of $n-3$ polyunsaturated fatty acids ( $\omega$-3) supplementation on some cardiovascular risk factors with a ketogenic Mediterranean diet. Marine drugs. 2015;13(2):996-1009. doi:10.3390/md13020996.

48. Desrochers S, Dubreuil P, Brunet J, Jetté M, David F, Landau BR, et al. Metabolism of ( $R$, S)-1,3-butanediol acetoacetate esters, potential parenteral and enteral nutrients in conscious pigs. Am J Physiol. 1995; 268(4 Pt 1):E660-7.

49. Clarke K, Tchabanenko K, Pawlosky R, Carter E, Knight N, Murray A, et al. Oral 28-day and developmental toxicity studies of (R)-3-hydroxybutyl (R)-3hydroxybutyrate. Regul Toxicol Pharmacol. 2012;63(2):196-208. doi:10.1016/j. yrtph.2012.04.001.

50. Clarke K, Tchabanenko K, Pawlosky R, Carter E, Todd King M, Musa-Veloso K, et al. Kinetics, safety and tolerability of (R)-3-hydroxybutyl (R)-3hydroxybutyrate in healthy adult subjects. Regul Toxicol Pharmacol. 2012; 63(3):401-8. doi:10.1016/j.yrtph.2012.04.008.

51. Warnick G, Knopp R, Fitzpatrick V, Branson L. Estimating low-density lipoprotein cholesterol by the Friedewald equation is adequate for classifying patients on the basis of nationally recommended cutpoints. Clin Chem. 1990;36(1):15-9.
52. Friedewald W, Levy R, Fredrickson D. Estimation of the concentration of low-density lipoprotein cholesterol in plasma, without use of the preparative ultracentrifuge. Clin Chem. 1972;18(6):499-502.

53. Harlan Laboratories Inc U. Sprague Dawley Outbred Rat. In: http://www. harlan.com/products_and_services/research_models_and_services/ research_models/sprague_dawley_outbred_rat.hl. 2008. http://www.harlan. com/products_and_services/research_models_and_services/research_ models/sprague_dawley_outbred_rat.hl. Accessed date January 30, 2014.

54. Inc TB. Sprague Dawley Rat. In: http://www.taconic.com/sd. 2014. http:// www.taconic.com/user-assets/documents/spraguedawley_booklet.pdf. Accessed date January 30, 2014.

55. McPherson P, McEneny J. The biochemistry of ketogenesis and its role in weight management, neurological disease and oxidative stress. J Physiol Biochem. 2012;68(1):141-51. doi:10.1007/s13105-011-0112-4.

56 Moore J, Eric C, Westman M. Cholesterol Clarity: What the HDL is Wrong With my Numbers. Las Vegas: Victory Belt Publishing Inc; 2013.

57 Dekaban A. Plasma lipids in epileptic children treated with the high fat diet. Arch Neurol. 1966;15(2):177-84.

58 Chesney D, Brouhard B, Wyllie E, Powaski K. Biochemical abnormalities of the ketogenic diet in children. Clin Pediatr. 1999;38(2):107-9. doi:10.1177/ 000992289903800207

59. Schwartz R, Boyes S, Aynsley-Green A. Metabolic effects of three ketogenic diets in the treatment of severe epilepsy. Dev Med Child Neurol. 1989;31(2):152-60.

60. Katyal N, Koehler A, McGhee B, Foley C, Crumrine P. The ketogenic diet in refractory epilepsy: the experience of Children's Hospital of Pittsburgh. Clin Pediatr. 2000;39(3):153-9. doi:10.1177/000992280003900303.

61. Ellenbroek J, van Dijck L, Töns H, Rabelink T, Carlotti F, Ballieux B, et al. Long-term ketogenic diet causes glucose intolerance and reduced beta and alpha cell mass but no weight loss in mice. Am J Physiol Endocrinol Metab. 2014;306(5):E552-8. doi:10.1152/ajpendo.00453.2013.

62. Bergqvist A. Long-term monitoring of the ketogenic diet: Do's and Don'ts. Epilepsy Res. 2012;100(3):261-6. doi:10.1016/j.eplepsyres.2011.05.020.

63. Groesbeck D, Bluml R, Kossoff E. Long-term use of the ketogenic diet in the treatment of epilepsy. Dev Med Child Neurol. 2006;48(12):978-81. doi:10. 1017/s0012162206002143.

64. Patel A, Pyzik P, Turner Z, Rubenstein J, Kossoff E. Long-term outcomes of children treated with the ketogenic diet in the past. Epilepsia. 2010;51(7): 1277-82. doi:10.1111/j.1528-1167.2009.02488.x.

65. Brehm BJ, Seeley RJ, Daniels SR, D'Alessio DA. A randomized trial comparing a very low carbohydrate diet and a calorie-restricted low fat diet on body weight and cardiovascular risk factors in healthy women. J Clin Endocrinol Metab. 2003;88(4):1617-23. doi:10.1210/jc.2002-021480.

66. Shai I, Schwarzfuchs D, Henkin Y, Shahar DR, Witkow S, Greenberg I, et al. Weight loss with a low-carbohydrate, Mediterranean, or low-fat diet. N Engl J Med. 2008:359(3):229-41. doi:10.1056/NEJMoa0708681.

67. Volek JS, Phinney SD, Forsythe CE, Quann EE, Wood RJ, Puglisi MJ, et al. Carbohydrate restriction has a more favorable impact on the metabolic syndrome than a low fat diet. Lipids. 2009;44(4):297-309. doi:10.1007/ s11745-008-3274-2.

68. Feinman RD, Volek JS. Low carbohydrate diets improve atherogenic dyslipidemia even in the absence of weight loss. Nutr Metab. 2006;3:24. doi: 10.1186/1743-7075-3-24.

69. Sharman MJ, Gomez AL, Kraemer WJ, Volek JS. Very low-carbohydrate and low-fat diets affect fasting lipids and postprandial lipemia differently in overweight men. J Nutr. 2004;134(4):880-5.

70. Sharman MJ, Kraemer WJ, Love DM, Avery NG, Gomez AL, Scheett TP, et al. A ketogenic diet favorably affects serum biomarkers for cardiovascular disease in normal-weight men. J Nutr. 2002;132(7):1879-85.

71. Westman EC, Mavropoulos J, Yancy WS, Volek JS. A review of lowcarbohydrate ketogenic diets. Curr Atheroscler Rep. 2003;5(6):476-83.

72. Wood RJ, Volek JS, Davis SR, Dell'Ova C, Fernandez ML. Effects of a carbohydrate-restricted diet on emerging plasma markers for cardiovascular disease. Nutr Metab. 2006;3:19. doi:10.1186/1743-7075-3-19.

73. Volek JS, Sharman MJ, Forsythe CE. Modification of lipoproteins by very low-carbohydrate diets. J Nutr. 2005;135(6):1339-42.

74. Volek JS, Westman EC. Very-low-carbohydrate weight-loss diets revisited Cleve Clin J Med. 2002;69(11):849. 53, 56-8 passim.

75. Volek JS, Sharman MJ, Gomez AL, DiPasquale C, Roti M, Pumerantz A, et al. Comparison of a very low-carbohydrate and low-fat diet on fasting lipids, LDL subclasses, insulin resistance, and postprandial lipemic responses in overweight women. J Am Coll Nutr. 2004;23(2):177-84. 
76. Volek JS, Sharman MJ. Cardiovascular and hormonal aspects of very-lowcarbohydrate ketogenic diets. Obes Res. 2004;12 Suppl 2:115s-23. doi:10. 1038/oby.2004.276

77. Volek JS, Sharman MJ, Gomez AL, Scheett TP, Kraemer WJ. An isoenergetic very low carbohydrate diet improves serum $\mathrm{HDL}$ cholesterol and triacylglycerol concentrations, the total cholesterol to $\mathrm{HDL}$ cholesterol ratio and postprandial pipemic responses compared with a low fat diet in normal weight, normolipidemic women. J Nutr. 2003;133(9):2756-61.

78. Schoeler NE, Wood S, Aldridge V, Sander JW, Cross JH, Sisodiya SM. Ketogenic dietary therapies for adults with epilepsy: feasibility and classification of response. Epilepsy \& behavior : E\&B. 2014;37:77-81. doi:10. 1016/j.yebeh.2014.06.007

79. Sengupta P. The laboratory Rat: relating its Age with Human's. Int J Prev Med. 2013;4(6):624-30

80. Tsuchiya N, Harada Y, Taki M, Minematsu S, Maemura S, Amagaya S. Age-related changes and sex differences on the serum chemistry values in Sprague-Dawley rats-I. 6-30 weeks of age. Exp Anim. 1995;43(5):671-8.

81. Saito K, Ishikawa M, Murayama M, Urata M, Senoo Y, Toyoshima K, et al. Effects of sex, age, and fasting conditions on plasma lipidomic profiles of fasted Sprague-Dawley rats. PLoS ONE. 2013;9(11):e112266. doi:10.1371/ journal.pone.0112266.

82. Ellington A, Kullo I. Atherogenic lipoprotein subprofiling. Adv Clin Chem. 2008:46:295-317.

83. Mudd J, Borlaug B, Johnston P, Kral B, Rouf R, Blumenthal R, et al. Beyond low-density lipoprotein cholesterol: defining the role of low-density lipoprotein heterogeneity in coronary artery disease. J Am Coll Cardiol. 2007:50(18):1735-41. doi:10.1016/j.jacc.2007.07.045

84. Sacks F, Campos H. Clinical review 163: cardiovascular endocrinology: Low-density lipoprotein size and cardiovascular disease: a reappraisal. Clin Endocrinol Metab. 2003:88(10):4525-32. doi:10.1210/jc.2003-030636

85. Wierzbicki A. Quality as well as quantity? Beyond low-density lipoproteincholesterol - the role of particle size. Int J Clin Pract. 2007;61(11):1780-2. doi: 10.1111/j.1742-1241.2007.01571.x

86. Tantibhedhyangkul P, Hashim S, Van Itallie T. Effects of ingestion of long-chain triglycerides on glucose tolerance in man. Diabetes. 1967;16(11):796-9. doi:10. 2337/diab.16.11.796.

87. Eckel R, Hanson A, Chen A, Berman J, Yost T, Brass E. Dietary substitution of medium-chain triglycerides improves insulin-mediated glucose metabolism in NIDDM subjects. Diabetes. 1992;41(5):641-7. doi:10.2337/diab.41.5.641.

88. Yost T, Erskine J, Gregg T, Podlecki D, Brass E, Eckel R. Dietary substitution of medium chain triglycerides in subjects with non-insulin-dependent diabetes mellitus in an ambulatory setting: impact on glycemic control and insulin-mediated glucose metabolism. J Am Coll Nutr. 1994;13(6): 615-22. doi:10.1080/07315724.1994.10718457.

89. Kashiwaya Y, Pawlosky R, Markis W, King MT, Bergman C, Srivastava S, et al. A ketone ester diet increases brain malonyl-CoA and Uncoupling proteins 4 and 5 while decreasing food intake in the normal Wistar Rat. J Biol Chem. 2010;285(34):25950-6. doi:10.1074/jbc.M110.138198.

90. Senior B, Loridan L. Direct regulatory effect of ketones on lipolysis and on glucose concentrations in man. Nature. 1968;219(5149):83-4.

91. Miles JM, Haymond MW, Gerich JE. Suppression of glucose production and stimulation of insulin secretion by physiological concentrations of ketone bodies in man. J Clin Endocrinol Metab. 1980;52(1):34-7. doi:10.1210/jcem-52-1-34.

92. Kristian HM, Thomas S, Niels HS, Thomas G, Gerrit van H. Systemic, cerebral and skeletal muscle ketone body and energy metabolism during acute hyper-D- $\beta$-hydroxybutyrataemia in post-absorptive healthy males. J Clin Endocrin Metabol. 2014. doi:10.1210/jc.2014-2608

93. Owen OE, Morgan AP, Kemp HG, Sullivan JM, Herrera MG, Cahill GF. Brain metabolism during fasting. J Clin Invest. 1967;46(10):1589-95. doi:10.1172/ JCl105650.

94. Papamandjaris AA, MacDougall DE, Jones PJ. Medium chain fatty acid metabolism and energy expenditure: obesity treatment implications. Life Sci. 1997;62(14):1203-15

95. Linde R, Hasselbalch S, Topp S, Paulson O, Madsen P. Global cerebral blood flow and metabolism during acute hyperketonemia in the awake and anesthetized rat. J Cereb Blood Flow Metab. 2006;26(2):170-80. doi:10.1038/ sj.jcbfm.9600177.

96. Azzam R, Azar N. Marked seizure reduction after MCT supplementation. Case reports in neurological medicine. 2013;2013:809151. doi:10.1155/2013/ 809151.
97. Corwin RL. Binge-type eating induced by limited access in rats does not require energy restriction on the previous day. Appetite. 2004;42(2):139-42. doi:10.1016/j.appet.2003.08.010

98. Keenan KP, Ballam GC, Dixit R, Soper KA, Laroque P, Mattson BA, et al. The effects of diet, overfeeding and moderate dietary restriction on SpragueDawley rat survival, disease and toxicology. J Nutr. 1997;127(5 Suppl):851S-6.

99. Keenan KP, Smith PF, Hertzog P, Soper K, Ballam GC, Clark RL. The effects of overfeeding and dietary restriction on Sprague-Dawley Rat survival and early pathology biomarkers of aging. Toxicol Pathol. 1994. doi:10.1177/ 019262339402200308

100. Kashiwaya Y, Bergman C, Lee J-H, Wan R, King M, Mughal M, et al. A ketone ester diet exhibits anxiolytic and cognition-sparing properties, and lessens amyloid and tau pathologies in a mouse model of Alzheimer's disease. Neurobiol Aging. 2013;34(6):1530-9. doi:10.1016/j.neurobiolaging.2012.11.023.

101. Birkhahn R, McCombs C, Clemens R, Hubbs J. Potential of the monoglyceride and triglyceride of DL-3-hydroxybutyrate for parenteral nutrition: synthesis and preliminary biological testing in the rat. Nutrition. 1997;13(3):213-9. doi:10.1016/s0899-9007(96)00404-2.

102. Puchowicz M, Smith C, Bomont C, Koshy J, David F, Brunengraber $H$. Dog model of therapeutic ketosis induced by oral administration of $R$, S-1,3-butanediol diacetoacetate. J Nutr Biochem. 2000;11(5):281-7.

103. Brunengraber $\mathrm{H}$. Potential of ketone body esters for parenteral and oral nutrition. Nutrition. 1997;13(3):233-5.

\section{Submit your next manuscript to BioMed Central and we will help you at every step:}

- We accept pre-submission inquiries

- Our selector tool helps you to find the most relevant journal

- We provide round the clock customer support

- Convenient online submission

- Thorough peer review

- Inclusion in PubMed and all major indexing services

- Maximum visibility for your research

Submit your manuscript at www.biomedcentral.com/submit

) BioMed Central 